\title{
Son Evre Glokomlu Gözlerde Trabekülektomi
}

\author{
Trabeculectomy in Eyes with End Stage Glaucoma
}

\section{Nurgül ÖRNEK ${ }^{1}$, Kemal ÖRNEK ${ }^{1}$, Reyhan OĞUREL ${ }^{1}$, İnci Elif ERBAHÇECí ${ }^{1}$, Zafer ONARAN ${ }^{1}$, Nesrin BÜYÜKTORTOP ${ }^{1}$, Tevfik OĞUREL ${ }^{1}$}

\author{
${ }^{1}$ Kırlkkale Üniversitesi Tip Fakültesi, Göz Hastalıkları Anabilim Dalı, KIRIKKALE.
}

\begin{abstract}
ÖZET
Son evre glokomlu hastaların gözlerinde trabekülektomi ameliyatının sonuçlarının değerlendirmek.

2010- 2013 tarihleri arasında son evre glokom tanıs1 olan 21 hastaya

(23 göz) yapılan trabekülektomi ameliyatına ait tıbbi kayıtlar geriye dönük olarak incelendi. Çalışmada her bir hasta için sonuç görme keskinliği, sonuç göz içi basıncı ve gelişen cerrahi komplikasyonlar değerlendirildi. Ameliyat sonrası elde edilen sonuçlar ameliyat öncesi verilerle istatistiksel olarak karşılaştırıldı.

Çalışmaya alınan hastaların 14'ü $(\%$ 66,7) erkek ve 7'si $(\% 33,3)$ kadındı. Hastaların ortalama yaşı $62,76 \pm 17,4$ yıl olarak bulundu. Ameliyat öncesi ortalama izlem süresi $14,3 \pm 15,6$ aydı. Ameliyat öncesi dönemde ortalama $35,9 \pm 9,2 \mathrm{mmHg}$ olan göz içi basıncı, postoperatif dönemde 12,8 \pm 4,7 $\mathrm{mmHg}$ seviyesine düştü $(\mathrm{p}<0,05)$. Kullanılan glokom ilacı sayısının ameliyat öncesi ortancası 4 olup, postoperatif dönemde sayı ortancası 1 seviyesine geriledi $(\mathrm{p}<0,05)$. Yirmi üç gözden iki tanesinde (\% 8,7) ameliyat sonrası dönemde görme keskinliğinde azalma meydana geldi. Görme keskinliğindeki azalmanın nedenleri bir gözde uzun süreli hipotoni, bir gözde de intraoperatif gelişen suprakoroidal kanama idi. Hiçbir gözde "wipeout fenomeni” ne bağlı görme kaybı oluşmadı.

Son evre glokomlu gözlerde trabekülektomi ameliyatı göz içi basıncını etkili şekilde düşürebilmektedir. Cerrahi komplikasyon gelişme olasıllı̆̆ ise beklenenden daha düşük görünmektedir.
\end{abstract}

Anahtar Kelimeler: Son evre glokom, trabekülektomi, cerrahi

* TOD 46. Ulusal Kongresinde poster olarak sunulmuştur.

\begin{abstract}
To evaluate the outcomes of trabeculectomy surgery in eyes of patients with end stage glaucoma.

Medical records of the 23 eyes of 21 patients who underwent trabeculectomy surgery with the diagnosis of end stage glaucoma between January 2010-January 2013 were evaluated retrospectively. Final visual acuity, final intraocular pressure and surgical complications were evaluated for each patient. The results were analyzed sttistically.

In the study, fourteen patients $(66,7 \%)$ were male and seven patients $(33,3 \%)$ were female. The mean age of the patients was $62,76 \pm 17,4$ years, the mean follow-up period was $14,3 \pm 15,6$ months. The mean preoperative intraocular pressure was $35,9 \pm 9,2 \mathrm{mmHg}$ and it reduced to $12,8 \pm 4,7 \mathrm{mmHg}$ postoperatively $(\mathrm{p}<0,05)$. The median of number of antiglocomatous medications was 4 before surgery and it reduced to median 1 in the postoperative period $(\mathrm{p}<0,05)$. Decreased visual acuity occured in 2 of 23 eyes $(8,7 \%)$. The causes of visual loss was a long term hypotony and introperative suprachoroidal hemorrhage. Neither of the eyes developed severe visual loss due to "wipe-out".

Trabeculectomy surgery lowers the intraocular pressure in eyes with end stage glaucoma. The probability of surgical complications in these eyes seems to be lower than expected.
\end{abstract}

Keywords: End stage glaucoma, trabeculectomy, surgery 


\section{GİRIŞ}

Glokom dünya üzerinde geri dönüşsüz körlük nedenleri arasında ikinci sırada yer almaktadır. Üzerinde kesin bir görüş birliği olmasa da, son evre glokom, ileri derecede daralmış bir görme alanı (< 10 derece) ya da düşük görme keskinliğinin $(<1 / 10)$ varlığı olarak tanımlanmaktadır. Son evre glokomlu gözlerde progresyon riski oldukça yüksektir. Hedef göz içi basıncı (GİB) başlangıçtaki ölçümlerden yaklaşık \%40 daha düşük olmalıdır. Bu gözlerde medikal tedavi başlangıçta etkili olsa bile hastanın tedaviye uyum zorluğu, ilaç tedavisinin yetersiz kalması ve ilaçlara bağlı gelişen toksik reaksiyonlar gibi nedenlerle kısa ya da uzun dönemde göz içi basıncında fluktuasyonlar olabilmektedir. $\mathrm{Bu}$ nedenle cerrahi tedavi bir seçenek olarak son evre glokomlu gözlerde mutlaka düşünülmelidir (1-6).

Son evre glokomlu gözlerde cerrahinin ne zaman ya da hangi kurallara göre yapılacağı kesinleşmiş değildir. Cerrahi tedavi medikal tedaviye göre göz içi basıncını daha fazla düşürse de, cerrahinin suprakoroidal kanama, postoperatif hipotoni, santral görmenin kaybedilmesi "wipe-out fenomeni" gibi çok ciddi komplikasyonları bulunmaktadır. Son evre glokomlu gözlerde uygulanan cerrahi yöntemlerin diğer tip glokomlu gözlerden önemli bir farkı bulunmamaktadır. Bazen açıyı açmak ve ön kamarayı derinleştirmek için trabekülektomi cerrahisi katarakt cerrahisi ile kombine de edilebilmektedir (1-6).

$\mathrm{Bu}$ çalışmada, son evre glokomlu gözlerde uyguladığımız trabekülektomi cerrahisinin sonuçlarını değerlendirmeyi amaçladık.

\section{GEREÇ VE YÖNTEM}

Kırıkkale Üniversitesi Hastanesi'nde 2010-2013 y1lları arasında son evre glokomlu gözlerde aynı cerrah (KÖ) tarafindan yapılan trabekülektomiler geriye dönük olarak değerlendirildi. Son evre glokom tanısı, tam ya da tama yakın nöroretinal rim hasarı ile terminal dönem görme alanı hasarının birlikte olması olarak tanımlandı. Cerrahi endikasyon ise maksimal medikal tedavi ile hedef göz içi basıncının elde edilememesi ya da hastanın tedaviye uyumsuzluğu olarak belirlendi.

Tüm cerrahiler retrobulber anestezi altında gerçekleştirildi. Glob cerrahi öncesi 8/0 vikril korneal traksiyon sütürü ile tespit edildi. Trabekülektomi 5 gözde saat 12 hizasından, 18 gözde ise temporal kadrandan gerçekleştirildi. Cerrahi yöntem kısaca, forniks tabanlı konjonktival flebin hazırlanması, 3 dakikalık subkonjonktival mitomisin $\mathrm{C}$ uygulamas1, $3 \times 3 \times 2 \mathrm{~mm}$ trapezoid lameller skleral flep diseksiyonu, yaklaşı $1 \mathrm{k} 2 \mathrm{~mm}$ sklerokeratektomi ve periferik iridektomi aşamalarından oluştu. Ameliyat sonrası tüm hastalara topikal antibiyotikli ve steroidli ilaçlar saat başı kullanım ile başlanıp, kullanım sıklığı azaltılarak 4-6 hafta sonunda kesildi. Sı̆̆ ön kamarası olan, hipotoni veya inflamasyon bulguları olan gözlerde ise ek olarak topikal sikloplejik kullanıld1.

Postoperatif dönem olarak hastaların en son muayenelerindeki verileri, trabekülektomi ameliyatı öncesi mevcut olan verilerle karşılaştırıldı. Çalışmanın sonunda sonuç görme keskinliği, sonuç göz içi basıncı ve cerrahi komplikasyonlar değerlendirildi. İstatistiksel analizde Student's t testi kullanıldı. Anlamlılık sınırı olarak $p<0.05$ değeri alındı.

\section{BULGULAR}

Çalışmaya 21 hastanın 23 gözü dahil edildi. Hastaların on dördü erkek $(\% 66,7)$, yedisi kadındı $(\% 33,3)$. Ortalama yaş $62,76 \pm 17,4$ (17-86) y1l olarak bulundu. On iki gözde $(\% 52,2)$ eksfolyatif glokom, 6 gözde $(\% 26,1)$ primer açık açılı glokom, 5 gözde $(\% 21,7)$ ise sekonder glokom mevcuttu (Tablo 1).

Tüm olgular cerrahi tedavi öncesi maksimum glokom tedavisi almaktaydı. Filtrasyon cerrahisi öncesinde ortalama medikal tedavi süresi $3,83 \pm 0,49$ y1l olarak bulundu. Ameliyat sonrası takip süresi ortalama $1,13 \pm 1,06$ yıldı. Trabekülektomi ameliyatı öncesi ortalama GİB 35,9 \pm 9,2 mmHg olarak bulunurken, trabekülektomi sonrası ortalama GİB miktarı 12,8 \pm 4,7 mmHg idi $(\mathrm{p}<0,05)$. Kullanılan anti- 
glokomatöz ilaç sayısı trabekülektomi ameliyatı öncesi ortalama $3,83 \pm 0,5$ olarak bulunurken, postoperatif dönemde ortalama $1,13 \pm 1,1$ idi $(\mathrm{p}<0,05)$ (Şekil 1).

Trabekülektomi ameliyatı öncesi cup/disk oranı (c/d) ortalama $0,92 \pm 0,49$ ve postoperatif dönemde de ortalama $0,92 \pm 0,52 \mathrm{idi}$; ameliyat öncesi ve postoperatif dönemde c/d oranları karşılaştırıldığında anlamlı farklılık saptanmadı ( $p>0,05)$. Hiçbir gözde "wipe-out fenomeni”ne bağlı görme kaybı oluşmadı. Yirmi üç gözden 2 tanesinde $(\% 8,7)$ gelişen komplikasyonlar nedeniyle görme keskinliğinde azalma oldu, diğer gözlerde görme keskinliği korundu. $\mathrm{Bu}$ komplikasyonlar bir gözde kronik hipotoni, bir gözde de intaoperatif gelişen suprakoroidal kanamaydı. Kronik hipotoni için öncelikle medikal tedavi uygulandı, daha sonra bleb üzerine argon lazer fotokoagülasyon yapıldı, göziçi basıncı $5 \mathrm{mmHg}$ seviyesinde kaldı. Suprakoroidal kanama gelişen hastada eksternal drenaj yapıldı ancak görme korunamad1.

Tablo 1: Ameliyat edilen gözlere ait demografik veriler.

\begin{tabular}{|c|c|c|c|}
\hline Hasta & Yaş (yıl) & Cins & Glokom tipi \\
\hline $1 \mathrm{a}$ & 65 & $\mathrm{E}$ & Psödoeksfolyatif glokom \\
\hline $1 b$ & 65 & $\mathrm{E}$ & Psödoeksfolyatif glokom \\
\hline 2 & 74 & K & Steroid glokomu \\
\hline 3 & 47 & $\mathrm{E}$ & Steroid glokomu \\
\hline 4 & 78 & $\mathrm{E}$ & Psödoeksfolyatif glokom \\
\hline 5 & 65 & K & Primer açık açılı glokom \\
\hline 6 & 57 & K & Psödoeksfolyatif glokom \\
\hline 7 & 86 & $\mathrm{E}$ & Primer açık açılı glokom \\
\hline 8 & 69 & $\mathrm{E}$ & Psödofakik glokom \\
\hline 9 & 72 & E & Psödoeksfolyatif glokom \\
\hline 10 & 55 & $\mathrm{E}$ & Psödofakik glokom \\
\hline 11 & 65 & K & Psödoeksfolyatif glokom \\
\hline 12 & 18 & K & Primer açık açılı glokom \\
\hline 13 & 79 & $\mathrm{E}$ & Psödoeksfolyatif glokom \\
\hline 14 & 66 & $\mathrm{E}$ & Primer açık açılı glokom \\
\hline 15 & 68 & $\mathrm{E}$ & Psödoeksfolyatif glokom \\
\hline 16 & 70 & $\mathrm{E}$ & Psödoeksfolyatif glokom \\
\hline 17 & 69 & K & Primer açık açılı glokom \\
\hline 18 & 57 & $\mathrm{E}$ & Primer açık açılı glokom \\
\hline 19 & 17 & K & Possner Schlossman Sendromu \\
\hline $20 \mathrm{a}$ & 73 & $\mathrm{E}$ & Psödoeksfolyatif glokom \\
\hline $20 b$ & 73 & $\mathrm{E}$ & Psödoeksfolyatif glokom \\
\hline 21 & 71 & $\mathrm{E}$ & Psödoeksfolyatif glokom \\
\hline
\end{tabular}




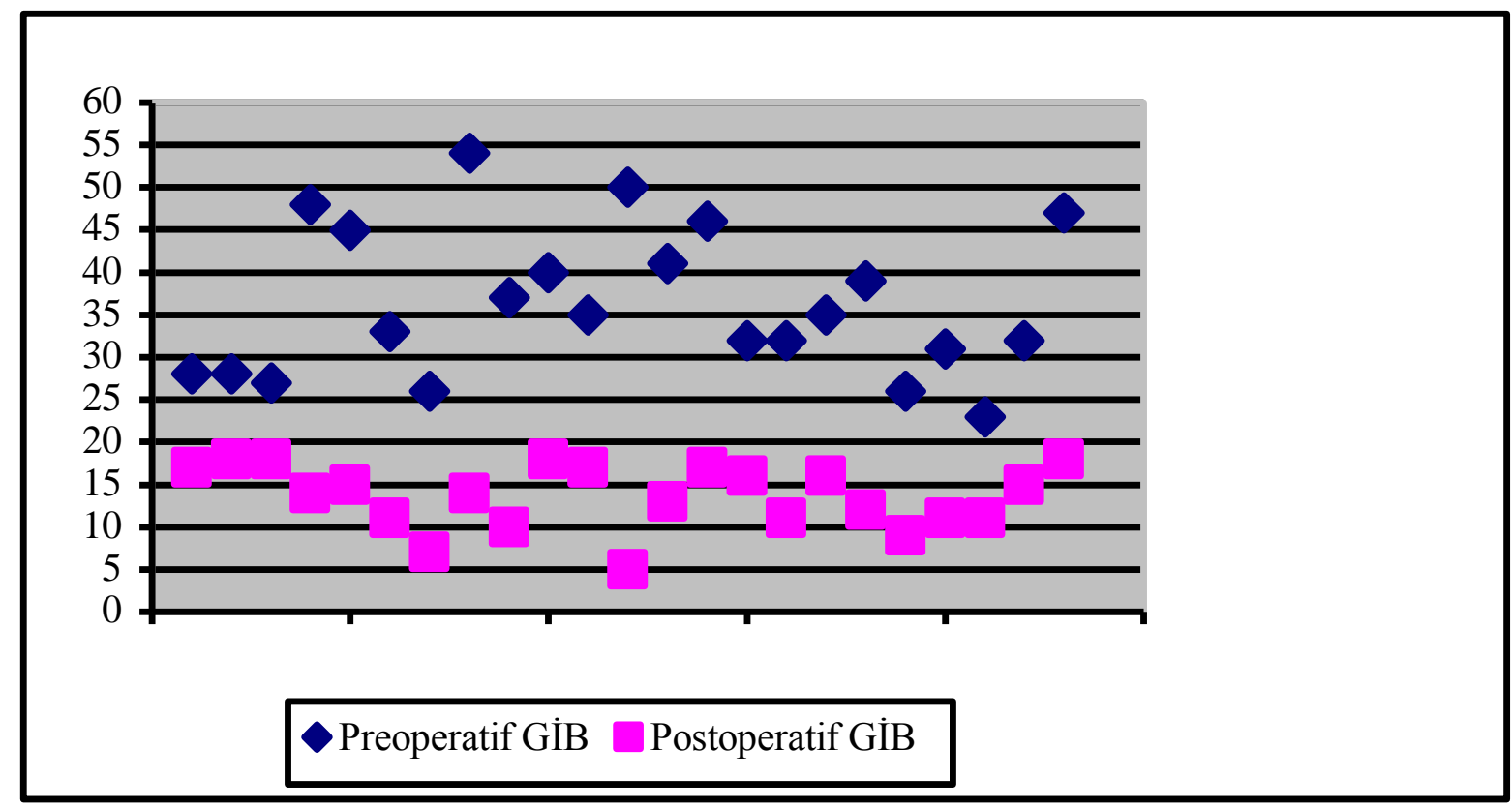

Şekil 1: Trabekülektomi öncesi ve sonrası göz içi basıncı dağılımı.

\section{TARTIŞMA}

Göz içi basıncı yüksek, görme alanı ileri derece hasarlı son evre glokomlu gözlerde hastalığın ilerleyerek kalan santral görmeyi de etkileme ihtimali yüksektir. Göz içi basıncı medikal ya da cerrahi olarak düşürülmelidir. Filtrasyon cerrahilerinin göz içi basıncını medikal tedavilere göre daha fazla düşürdüğü bilinen bir gerçektir (7,8). Cerrahlar bu hastalara ameliyat önerirken nadir görülen "wipe-out" fenomeni nedeniyle yeterince kararlı olamayabilmektedir. Bu korkutucu durumun gelişme sıklığı yaklaşık \%6 olarak bildirilmektedir (4). Ancak farklı çalışmalarda farklı oranlar da verilmektedir (3-6). Yapılan araştırmalar bu komplikasyonun intraoperatif hipotoni ya da mikroembolilere bağlı optik sinir başının etkilenmesine bağlı olabileceğini göstermektedir.

Agarwal ve Hendels, 26 son evre glokomlu gözde mitomisin C kullanarak yaptıkları trabekülektomi sonrası 4 gözde görme kaybı $(\% 15,4)$ ile karşılaşmıştır (3). Costa ve arkadaşlarının 508 gözü içeren oldukça geniş serisinde ise bu oran \%0.95 olarak bulunmuş ve yazarlar "wipe-out" fenomeninin sanıldığının aksine nadir bir durum olduğunu belirtmiştir (4). Awai ve arkadaşlarının son evre glokomlu gözlerde trabekülektomi ameliyatı sonrası 2 aylık takip döneminde göz içi basıncı düşük olarak izlenmiştir. Hiçbir olguda "wipe-out” gelişmemiştir (5). Law ve arkadaşlarının 117 gözde gerçekleştirdikleri trabekülektomi ameliyatı sonrası 7 gözde görmede azalma olmuş, bunlardan üç gözde hipoton makulopatisi, iki gözde göz içi basıncı artışı, bir gözde inflamasyon ve bir gözde ise katarakt gelişimi nedeniyle görme kaybı ile karşılaşılmıştır. Hiçbir gözde "wipe-out" fenomeni oluşmamıştır (6).

Bizim çalışma grubumuzda da "wipe-out" fenomeni görülmemiş ancak iki gözde gelişen komplikasyonlar (kronik postoperatif hipotoni ve inraoperatif suprakoroidal kanama) nedeniyle görmede azalma olmuştur. Yüksek preoperatif GİB, preoperatif ve postoperatif GIBB arasındaki fark veya sistemik hipertansiyon varlığı suprakoroidal kanama için risk faktörleridir $(9,10)$. Bu faktörlerle beraber kombine katarakt ve glokom cerrahisi yapılan bu olguda enjektörle implante edilen lensin teması ile birlikte gelişen arka kapsül rüptürü suprakoroidal kanamaya yol açmış olabilir.

Bizim serimizde trabekülektomi ameliyatı sonrası GİB'de anlamlı azalma mevcuttu ve kullanılan anti glokomatöz ilaç sayısı da trabekülektomi ameliyatı öncesine göre anlamlı olarak azalmıştı. Topouzis ve arkadaşları 21 son evre glokomlu hastada trabekülektomi cerrahisi uygulamışlar; GİB'de $14,1 \pm 9,2 \mathrm{mmHg}$ azalma sağlamışlar, postoperatif dönemde kullanılan antiglokomatöz ilaç sayısı da anlamlı derecede azalmıştır (2).

Sonuç olarak, son evre glokomlu gözlerde trabekülektomi ameliyatı sonrası orta dönemde göz içi basıncı düşük ve stabil seyretmektedir ve 
komplikasyon gelişme olasılığının beklenenden düşük olduğu görülmektedir. Bu nedenle son evre glokomlu gözlerde endikasyon durumunda trabekülektomi ameliyatı yapmaktan kaçınılmamalıdır

\section{KAYNAKLAR}

1. Gillies WE, Brooks AM, Strang NT. Management and prognosis of end stage glaucoma. Clin Experiment Ophthalmol. 2000; 28(6): 405-08.

2. Topouzis F, Tranos P, Koskosas A, Pappas T, Anastasopoulos E, Dimitrakos S, Wilson MR. Risk of sudden visual loss following filtration surgery in end-stage glaucoma. Am J Ophthalmol. 2005; 140(4): 661-6.

3. Aggarwal SP, Hendels S. Risk of sudden visual loss following trabeculectomy in advanced primary open-angle glaucoma. $\mathrm{Br}$ J Ophthalmol. 1986; 70(2): 97-9.

4. Costa VP, Smith M, Spaeth GL, Gandham S, Markovitz B. Loss of visual acuity after trabeculectomy. Ophthalmology. 1993; 100(5): 599-612.

5. Awai $M$, Koga $T$, Inatani $M$, Inoue $T$, Tanihara $H$. Stability of the central visual field after modern trabeculectomy techniques in eyes with advanced glaucoma. Jpn J Ophthalmol. 2007; 51(2): 116-20.
6. Law SK, Nguyen AM, Coleman AL, Caprioli J. Severe loss of central vision in patients with advanced glaucoma undergoing trabeculectomy. Arch Ophthalmol. 2007; 125(8): 1044-50.

7. Lichter PR, Musch DC, Gillespie BW, Guire KE, Janz NK, Wren PA, Mills RP; CIGTS Study Group. Interim clinical outcomes in the Collaborative Initial Glaucoma Treatment Study comparing initial treatment randomized to medications or surgery. Ophthalmology. 2001; 108: 1943-53.

8. Migdal C, Gregory W, Hitchings R. Long-term functional outcome after early surgery compared with laser and medicine in open-angle glaucoma. Ophthalmology. 1994; 101: 1651-57.

9. No authors listed. Risk factors for suprachoroidal hemorrage after filtering surgery. The Fluorouracil Filtering Surgery Study Group. Am J Ophthalmol. 1992; 113: 501-7.

10. Jeganathan VS, Ghosh S, Ruddle JB, Gupta V, Coote MA, Crowston JG. Risk factors for delayed suprachoroidal hemorrage following glaucoma surgery. Br J Ophthalmol. 2008; 92: 1393-6. 